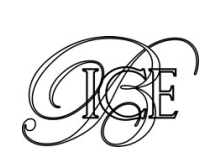

Fernando Zapico Teijeiro*

\title{
EL IDIOMA ESPAÑOL EN FILIPINAS El valor de lo propio
}

El imparable avance del idioma español en el mundo contrasta con la situación que la lengua de Cervantes atraviesa en Filipinas. Este artículo pretende presentar las causas que han conducido al debilitamiento del idioma español en el archipiélago, poniéndolo al borde de la desaparición como lengua materna, y recoger diversos datos que permiten ser optimistas de cara a una futura recuperación del protagonismo de la lengua española en una sociedad que empieza a percibir el valor que aporta el conocimiento de un idioma que, además de ser propio de Filipinas -porque sin él no se puede acceder a muchas de las claves de la identidad nacional- aporta un enorme valor añadido, abriéndoles a los jóvenes perspectivas laborales muy halagüeñas.

Palabras clave: Filipinas, español, política educativa, emigración, empleabilidad, identidad cultural. Clasificación JEL: I23, I25, I28.

\section{Introducción}

«Los que cifran su verdad en la estadística tienen ganada la partida si se trata de calibrar la presencia española en Filipinas en función del número de hispano-hablantes. El resultado negativo es obvio, con su carga de pesimismo. Acepto el resultado, pero no su connotación adversa. Somos una minoría los filipinos que poseemos el idioma español en relación con la totalidad de la población nacional».

Así de contundente se manifestaba el historiador, abogado, diplomático y lingüista Antonio Memije Molina en su ensayo ¿Qué queda de España en Filipinas? (Molina, 1998) ${ }^{1}$.

Desde entonces, la lucha por mantener viva la lengua española en el archipiélago ha continuado sin tregua alguna. Con momentos de mayor esperanza, como la que se desencadenó a partir de la visita de la presidenta Gloria Macapagal y su ministro

\footnotetext{
* Asesor de Educación de la Embajada de España en Filipinas. Versión de abril de 2016.

1 Presentado en la Sociedad Española de Estudios de la Comunicación Iberoamericana (SEECI).
}

de Educación, Jesli Lapus, a España en 2007 y 2008 y el consiguiente anuncio de reintroducción de las enseñanzas de español en el sistema público de educación, y con periodos de incertidumbre y desasosiego notables, la batalla por la supervivencia del español como lengua de comunicación en tierras filipinas no ha cesado.

Sin duda, las palabras del gran hispanista Antonio M. Molina reflejan un sentimiento común entre quienes tenemos la fortuna de residir y trabajar en Filipinas y nos enfrentamos diariamente a la paradoja de que, en un momento en que la pujanza del español en el mundo es extraordinaria, nuestro idioma está a punto de desaparecer como lengua materna en un país en el que España estuvo presente durante más de tres siglos.

\section{Causas del declive del español en Filipinas}

Resulta imposible comprender la situación de la lengua española en Filipinas, así como las perspectivas de futuro que se están abriendo para nuestro $\triangle$ 
idioma, sin revisar brevemente la política lingüística llevada a cabo por las autoridades españolas durante el periodo colonial, por los estadounidenses durante las cinco décadas en las que ejercieron un férreo control directo sobre el archipiélago y, sobre todo, por los legisladores filipinos desde 1946 hasta el momento actual.

El principal debate que ha ocultado, en parte, las verdaderas causas del declive del español se ha centrado en determinar si este idioma llegó a convertirse en lengua de comunicación generalizada entre la población filipina. Se trata de un debate muy enconado y, en mi opinión, estéril, porque sin negar que la Administración española no planificó una política de enseñanza generalizada del idioma hasta finales del siglo XIX, lo realmente relevante se refiere al hecho de que el español era el idioma en el que se impartía la enseñanza universitaria en las instituciones más prestigiosas del país, que se utilizaba en los ámbitos de la política y el derecho y que la mayor parte de la prensa se publicaba en este idioma. Es decir, que la lengua de Cervantes fue lengua de prestigio en Filipinas hasta la Segunda Guerra Mundial, incluso durante el periodo de administración del archipiélago por los Estados Unidos de América.

Sin quitar un ápice de importancia a la estrategia de destrucción planificada de cualquier elemento cultural hispano diseñada por los estadounidenses, no se pueden obviar otros tres elementos que han sido claves en el proceso de paulatina desaparición del español en Filipinas (porque ésta y no otra es la realidad actual que hay que reconocer para poder diseñar una estrategia de futuro).

\subsection{La creación de la lengua nacional}

La ola de afirmación nacionalista que se desencadenó tras la independencia condujo a la creación de un idioma nacional basado en una de las lenguas locales, al contrario de lo sucedido en las naciones de América Central y del Sur.

El español podría haberse convertido en lengua nacional si se hubiera valorado que los héroes de la independencia filipina habían escrito sus obras en este idioma, el mismo que sirvió para redactar la Constitución de Malolos o para componer la letra del himno nacional por encargo del presidente Aguinaldo. Pero la obsesión por imponer el tagalo como lengua nacional se impuso, contribuyendo enormemente a la gradual desaparición del español de la vida diaria de los filipinos.

Justo es reconocer, también, que muchos legisladores intentaron mantener el español presente en el sistema educativo con la aprobación de varias normas que hacían obligatorio su estudio en el nivel universitario, y que se mantuvo como una de las lenguas oficiales de la República de Filipinas hasta que la Constitución de 1987 abrogó este aspecto? ${ }^{2}$.

Tres fueron las leyes que promulgaron los legisladores filipinos para fomentar las enseñanzas de español en el sistema educativo. En primer lugar, la Ley Sotto de $1949^{3}$, que incluía la lengua española como una de las materias optativas para los estudiantes de secundaria. Más incisiva fue la Ley Magalona de $1952^{4}$, que convertía en obligatoria la enseñanza de doce unidades de español en todas las universidades y escuelas privadas durante dos años consecutivos. Y lo que es más, la ley recogía la imposibilidad de ofertar cualquier nueva titulación si el $\triangleright$

\footnotetext{
2 Así, la Constitución de Malolos de 1899, redactada originalmente en español, señalaba en su artículo 93 que «para los actos de la autoridad pública y los asuntos judiciales [...] se usará por ahora la lengua castellana». La Constitución de 1935, promulgada todavía en inglés y en español, señalaba en su artículo XIII.3 que «la Asamblea Nacional dará pasos hacia el desarrollo y adopción de una lengua común nacional común basada en una de las lenguas nativas existentes", aunque concede que "hasta que la ley disponga otra cosa, el inglés y el español continuarán como lenguas oficiales». La Constitución de 1943 no mencionaba una lengua oficial, pero establecía en su artículo Ix.2 que «el Gobierno dará pasos para el desarrollo y propagación del tagalo como lengua nacional». La de 1973 señala que «se promulgará oficialmente en inglés y en filipino" con la obligación de traducirla también al español y el árabe (artículo xxv.3), perdiendo entonces el español por primera vez el carácter de lengua oficial, aunque tan sólo a nivel constitucional, ya que un decreto presidencial publicado unos meses después (Decreto 155 de 15 de marzo de 1973) estableció que «el idioma español continuará siendo reconocido como lengua oficial en Filipinas mientras persistan documentos importantes en los archivos del Gobierno que estén en español y no hayan sido traducidos al inglés o al filipino". La Constitución de 1987 establece que «la lengua nacional de Filipinas es el filipino» (artículo XIV.6) y que «para propósitos de comunicación e instrucción las lenguas oficiales de Filipinas serán el filipino y, hasta que la ley disponga otra cosa, el inglés «, recomendando tan sólo la promoción del español (junto con el árabe) «con carácter voluntario y opcional» (artículo xIV.7).

${ }^{3}$ Ley 343 de la República de Filipinas, aprobada el 26 de febrero de 1949.

${ }^{4}$ Ley 709 de 5 de junio de 1952.
} 
español no se incluía en el currículo. Por último, en 1957 fue aprobada la Ley Cuenco ${ }^{5}$, que aumentaba a 24 el número de unidades de español que debían completarse en enseñanzas como pedagogía, derecho, comercio, humanidades y servicio exterior, aunque una nueva norma de $1967^{6}$ redujo la duración de las enseñanzas de español a la mitad, 12 créditos 7 .

Rodao (1996) considera que estas leyes supusieron la estocada definitiva para el español en Filipinas, dado que la imposición obligatoria fue rechazada masivamente por los estudiantes universitarios y ayudó a extender un sentimiento antiespañol.

Al margen de las manipulaciones políticas que llevaron a cabo los sectores más favorables a las posiciones estadounidenses, y sin quitar un ápice de mérito a muchos de los docentes que se hicieron cargo de la enseñanza de español, lo cierto es que estas leyes educativas no produjeron los efectos deseados.

El número de profesores necesario para poner en marcha programas de enseñanza tan ambiciosos era enorme, y muchos de los que se hacían cargo de las labores docentes carecían de la preparación adecuada. Además, la mitad del currículo se dedicaba a memorizar textos literarios en los que la visión que se presentaba de España no era precisamente muy positiva. Esta combinación de un enfoque pedagógico muy alejado de las destrezas comunicativas y una visión sesgada de lo hispano han resultado letales para las enseñanzas de español.

\subsection{La influencia estadounidense}

Filipinas no podía sustraerse a lo sucedido tras la Segunda Guerra Mundial, cuando EEUU se convirtió realmente en la fuerza dominante, no sólo en el ámbito político, militar y económico, sino también en el de la investigación, la cultura y la educación.

\footnotetext{
${ }^{5}$ Ley 1881 de 22 de junio de 1957.

${ }^{6}$ Ley 5182 de 8 de septiembre de 1967.

${ }^{7}$ Equivalentes a tres horas semanales durante cuatro cursos (Quilis y Casado, 2008).
}

Aunque parezca una obviedad, hay que recordar que el inglés sólo se convierte en lengua de prestigio mundial a partir de las guerras mundiales, e incluso se puede decir que esta extensión no tuvo lugar hasta finales de la década de los setenta.

Crystal (2004) analiza las causas por las que el inglés se ha convertido en la nueva lingua franca mundial y señala los diez elementos claves en este sentido: dominio político, desarrollo económico, prensa, publicidad, radiodifusión, música, cinematografía, viajes internacionales, seguridad, comunicaciones y educación. Todos estos elementos se identifican perfectamente en la evolución de la sociedad filipina, no sólo bajo el dominio directo estadounidense, sino también en el periodo posterior a la independencia. La verdad es que pocos países han sido tan permeables a la influencia anglosajona como Filipinas.

\subsection{La desconexión entre España y Filipinas}

En coherencia con la escasa presencia española en su territorio asiático se produce una casi completa desconexión entre ambos países que pone de manifiesto las enormes dificultades que las autoridades de la metrópoli percibían para mantener una relación fluida con su territorio. Comparar lo sucedido con Filipinas y Cuba tras la pérdida de ambas colonias en 1898 nos da una buena idea de la muy diferente visión con la que desde España se contemplaba a ambos territorios.

Y esta última es probablemente la causa más determinante en la práctica desaparición del español de la sociedad filipina: la total ausencia de referentes hispanos. Parece que tienen razón quienes afirman que la pérdida de Filipinas provocó en España un cierto sentimiento de alivio en lugar de vivirse como una tragedia y se cumple así la profecía del director de educación de la Administración estadounidense en Filipinas, quien, en su octavo informe sobre la situación educativa del país, señalaba que el elemento clave para predecir la desaparición del español en este enclave asiático $\triangleright$ 
sería la ausencia de contactos entre el archipiélago y el resto de las naciones hispanohablantes (Barrows, 1907).

\section{Perspectivas del español en Filipinas}

A pesar de esta gran ausencia de presencia hispana en Filipinas, las perspectivas de crecimiento del español no son malas. Y no pueden serlo porque estamos hablando de uno de los idiomas más pujantes del mundo debido a una serie de factores que lo convierten en una lengua con gran valor económico: por número de hablantes del idioma como lengua materna, por número de países en los que es lengua oficial y de uso común y, sobre todo, debido al exponencial crecimiento demográfico de los hispanos en EEUU, que se han convertido en un grupo clave para las empresas, los medios de comunicación y los partidos políticos de este país.

Filipinas es un país en vías de desarrollo, en el que lo inmediato se impone casi siempre a los planes a medio y largo plazo. Los numerosos y generosos programas de becas de determinados países que aspiran a expandir su influencia política, económica y cultural en Filipinas (Japón, Corea, Estados Unidos, Canadá o Australia) hacen que grupos de estudiantes abandonen inmediatamente la lengua extranjera que están estudiando para intentar aprovechar las oportunidades que les ofrece el estudio de lenguas que les permitirá sufragarse estudios que de otro modo no podrían completar. Este hecho, la inmediatez, que en ocasiones ha perjudicado las expectativas del español en Filipinas, se ha convertido en este momento en un aliado clave que explica el interés por aprender nuestra lengua.

De hecho, y a pesar de que la Comisión de Educación Superior no dispone de estadísticas oficiales, se puede constatar que, en la práctica, en la totalidad de universidades en las que se ofrecen estudios de lengua extranjera el español, es la primera opción de los estudiantes filipinos (Ministerio de Educación, Cultura y Deporte, 2015). Además, el Instituto
Cervantes de Manila es uno de los más importantes de la red ${ }^{8}$.

El valor económico del español en Filipinas se centra en cuatro sectores diferentes: las instituciones educativas y culturales, la industria de externalización de procesos de negocios (BPO), el sector educativo y los trabajadores filipinos en el exterior, que analizamos a continuación.

\subsection{Instituciones educativas y culturales}

En primer lugar, a medida que el país avanza en su desarrollo económico, y los sectores educativo e investigador comienzan a contar con un presupuesto más generoso que les permite ampliar su campo de acción, las instituciones se encuentran con una barrera lingüística que les impide acceder a un gran número de fuentes primarias en disciplinas históricas, legales, médicas, educativas o literarias. Los tres siglos largos de presencia española en Filipinas supusieron la creación de un aparato administrativo, la aplicación de un código legal y la puesta en marcha de importantes centros de investigación científica como el Observatorio de Manila. Muchos de los documentos originales se han perdido como consecuencia de los numerosos desastres naturales o de los conflictos que se han vivido en el país, pero otra gran mayoría permanecen almacenados sin que el personal que está a cargo de los centros pueda tener acceso directo a ellos al carecer de las herramientas lingüísticas necesarias para desarrollar correctamente su labor.

Algunas instituciones, como la Comisión Histórica Nacional, se han fijado como meta formar grupos de investigadores que dominen el español. Esta tendencia sólo puede ir en aumento en un país que aspira a integrarse en un espacio de educación superior regional en el que se valora especialmente la actividad investigadora.

\footnotetext{
${ }^{8}$ El Instituto Cervantes de Manila registró en el último año académico completado (2014-2015) un total de 6.201 matrículas. El Cervantes de Manila es un centro regional, que coordina los Institutos Cervantes de AsiaPacífico (Tokio, Pekín, Nueva Delhi y Sidney) y del que dependen además las aulas de Hanoi, Yakarta y Kuala Lumpur.
} 


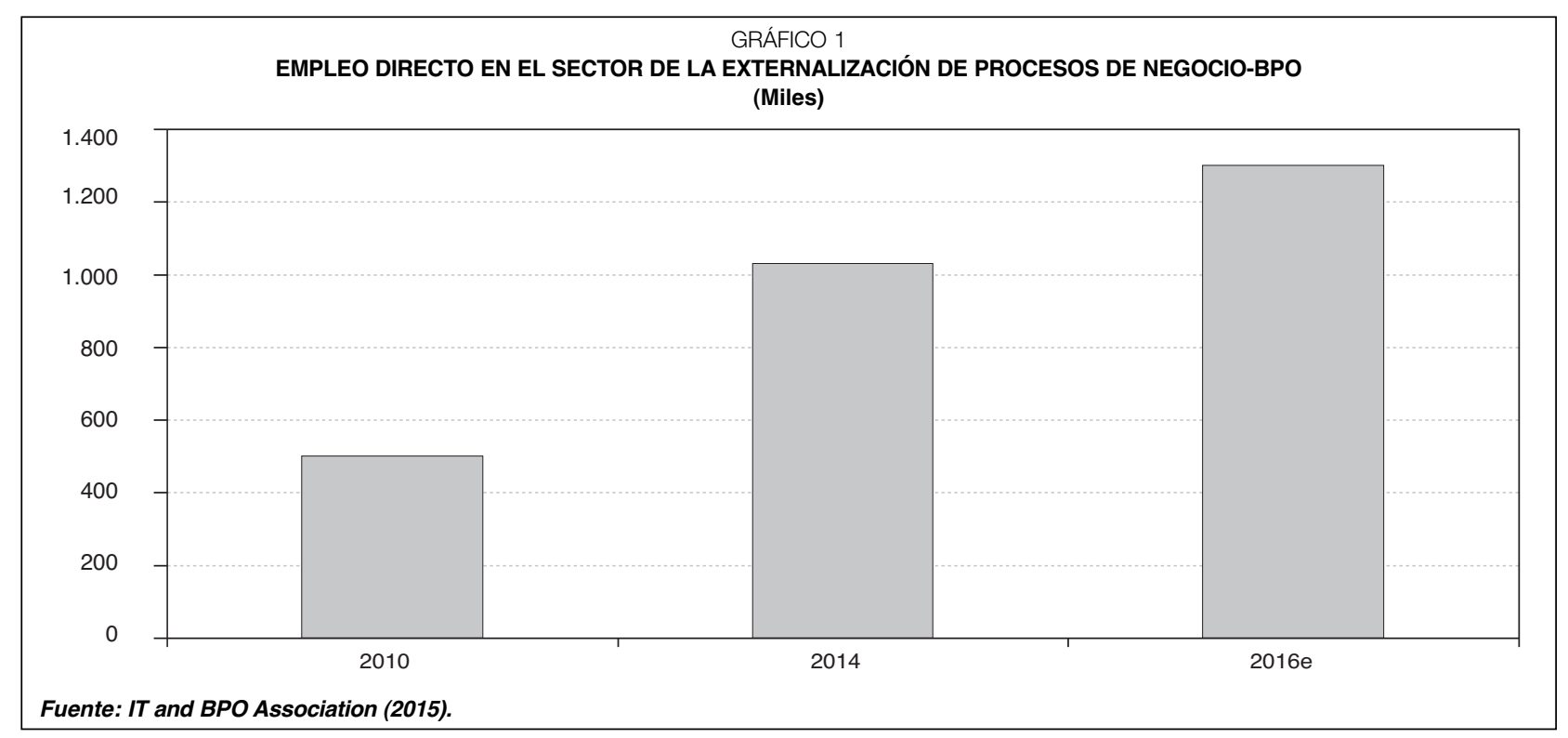

\subsection{La industria de externalización de procesos de negocios (Business Processing Outsourcing o BPO)}

El español ya es, en este momento, un elemento que abre perspectivas laborales muy interesantes en Filipinas. Este país se ha convertido, en un breve periodo de tiempo, en el centro de la industria de externalización de procesos de negocios, superando a India.

La asociación filipina de BPO calcula que en 2016 generará 25.000 millones de dólares y aportará el 8,3 por 100 del PIB, empleando a 1,3 millones de trabajadores (IBPAP, 2015). Aunque no existen estadísticas sobre el número de empleos vinculados al conocimiento del español, lo cierto es que más del 70 por 100 del negocio se dirige a Estados Unidos, con sus más de 40 millones de hispanohablantes.

Los buscadores de empleo muestran cientos de trabajos para agentes bilingües español-inglés. Se trata, además, de trabajos que ofrecen salarios competitivos (entre 40.000 y 60.000 pesos filipinos de salario inicial, triplicando el de profesiones como la enseñanza o la enfermería).

En el caso de Filipinas, el valor añadido que ofrece el aprendizaje de español es muy superior al de otras lenguas extranjeras. Como muy bien señalaba el semanario The Economist ${ }^{9}$, el juego entre la oferta y la demanda determina la diferencia de valor que ofrecen las diversas lenguas. Si el español se hubiera mantenido como segunda lengua en Filipinas, podríamos encontrarnos con una situación en la que el aprendizaje de nuestra lengua resultara menos rentable que el de otras al ser elevado el número de hablantes bilingües.

Sin embargo, la enorme escasez de hablantes de español hace que cualquier acontecimiento internacional (en 2015 y 2016 la visita del Papa, la cumbre de APEC y el Congreso Eucarístico Mundial) provoque una demanda de intérpretes que no suele ser cubierta de forma satisfactoria. Evidentemente, la escasez de oferta supone un aumento muy notable de las tarifas que ofrecen los organizadores.

Esta es la misma situación con la que se encuentran los directivos de los BPO que, en muchos casos, recurren a personal expatriado para que se haga cargo de parte del negocio que se centra en EEUU e Hispanoamérica.

\subsection{El sector educativo}

Filipinas se enfrenta ahora al reto de poner en marcha una reforma educativa que homologue su $\triangleright$

\footnotetext{
9 «Johnson: What is a foreign language worth?» (11 de marzo de 2014)
} 


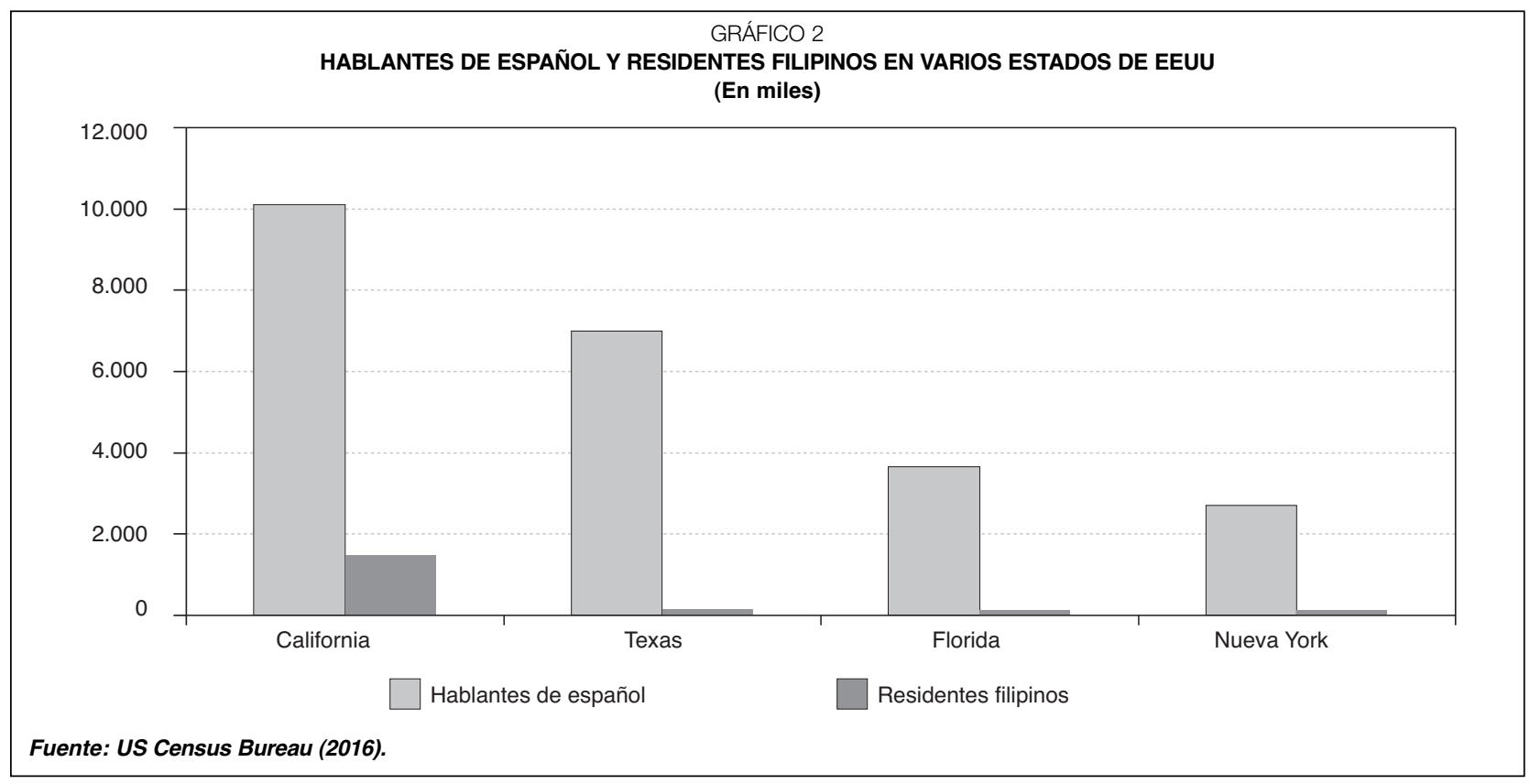

sistema al del resto de los países del Sudeste Asiático, ampliando de diez a doce los años de enseñanza preuniversitaria. En este nuevo currículo, en el que han venido trabajando conjuntamente el Departamento de Educación y la Comisión de Educación Superior, aparecerán por primera vez las lenguas extranjeras como materias optativas.

Se señala con cierta frecuencia que no existen departamentos de español como tales en las universidades filipinas, y que tan sólo una institución de educación superior -la Universidad de Filipinasoferta un Grado en estudios hispánicos. Se compara, además, este hecho innegable con la realidad de países como Corea, Japón, Vietnam o Camboya, donde -con muchos menos lazos históricos y culturales- el número de universidades que ofrecen estudios hispánicos es mucho mayor.

Ahora bien, las realidades socioeconómicas y políticas de estos cuatro países que se citan con tanta frecuencia explican en parte esta situación. En el caso de Vietnam y Camboya, los intercambios académicos y las políticas de colaboración económica con Cuba y Venezuela han supuesto un movimiento de ciudadanos camboyanos y vietnamitas a países hispanohablantes donde recibían educación universitaria en español.

En el caso de Corea y Japón, estamos hablando de países que figuran entre los veinte primeros en el Índice de Desarrollo Humano que elabora anualmente el Programa de Naciones Unidas para el Desarrollo. Filipinas lleva varios años estabilizado en torno al puesto 115.

En Filipinas, los estudios de humanidades reciben muy pocos alumnos, en claro contraste con las enseñanzas de ingeniería o informática. La empleabilidad es el principal criterio que utilizan a la hora de elegir carrera una mayoría de estudiantes que necesitan conseguir ingresos a corto plazo.

El sistema educativo filipino necesitará de miles de profesores de lenguas $y$, aunque los sueldos en la docencia aún son bajos, el número de estudiantes de los programas de formación del profesorado en los que se imparta español será elevado.

\subsection{Los trabajadores filipinos en el exterior (Overseas Filipino Workers)}

Estos trabajadores son una de las principales fuentes de ingresos del país. Según las últimas estadísticas publicadas por el Departamento de Trabajo y Empleo, casi un 10 por 100 de la población del país reside en el exterior -aproximadamente un 10 por 100 del censo- representando, las remesas enviadas por estos trabajadores, casi un 9 por 100 del producto interior bruto del país. 
¿En qué medida afectan estos datos a la realidad lingüística de Filipinas? El principal país receptor de emigrantes filipinos es Estados Unidos de América, donde residen más de dos millones. De ellos, más de un millón viven en el estado de California, mientras estados como Texas o Nueva York cuentan al menos con unos cien mil residentes filipinos en cada uno de ellos.

Nos encontramos, pues, con un escenario en el que los filipinos que han emigrado a Estados Unidos conviven con un alto porcentaje de hispanohablantes. Según los datos de la oficina del Censo de EEUU (US Census Bureau, 2016), en 2013 casi 40 millones de personas hablaban español (y otros 11 millones eran bilingües). De ellos, más de diez millones se encuentran en California, siete en Texas, y casi tres en Nueva York. Esto significa que casi la mitad de los hispanohablantes se concentran en los estados en los que residen 1,5 millones de filipinos.

No es objeto de este artículo presentar los elementos que muestran la vitalidad y pujanza del español en Estados Unidos, pero podemos afirmar, sin temor a equivocarnos, que incluso los sectores de las autoridades filipinas que más reservas muestran hacia la lengua y cultura españolas, empiezan a reconocer la importancia que nuestro idioma está adquiriendo en un contexto de desarrollo global en el que empresas e instituciones públicas de numerosos estados de EEUU comienzan a valorar el español como un mérito y, en algunas ocasiones, como requisito para obtener numerosos puestos de trabajo.

\section{Conclusiones}

Sólo un cambio político muy brusco volvería a convertir al español en una lengua nacional en Filipinas, pero, indudablemente, la población general acabará por percibir las enormes ventajas de aprender un idioma que, además de constituir parte innegable de su propia cultura y permitirles acceder a las principales fuentes históricas de su país incrementará sus oportunidades laborales.
Que uno de los factores que más pueda contribuir a la recuperación del español en Filipinas pueda ser el incremento de hispanohablantes en EEUU, no deja de tener su interés. Estaría, así, a punto de confirmarse lo que afirmaba el escritor chileno Jorge Edwards en la entrevista publicada en el diario El Tiempo, con motivo de su ponencia en la inauguración del VII Congreso Internacional de la lengua española celebrado en Puerto Rico en marzo de 2016, al referirse al crecimiento de la lengua española en los EEUU: «Es una revancha. Es una revancha en cierto modo... Es una revancha importante, interesante y muy fuerte ${ }^{10}$.

Se empieza a visualizar la posibilidad de que quienes con tanto ahínco se empeñaron en erradicar el español de la Perla de Oriente sean ahora responsables de su retorno.

Y, para acelerar la consecución de este objetivo, es esencial que en esta ocasión las instituciones españolas colaboren de forma decidida, porque la agonía de la lengua española en Filipinas no ha supuesto nunca una merma en el innegable carácter hispánico de esta nación hermana.

\footnotetext{
10 El Tiempo, 19 de marzo de 2016.
}

\section{Bibliografía}

[1] BARROWS, D. (1907). «Education and Social Progress in the Philippines". The Annals of the American Academy of Political and Social Science, vol. 30, pp. 69-82. American Colonial Policy and Administration. Disponible en: http://www.jstor.org/stable/1010635

[2] CRYSTAL, D. (2005). La Revolución del lenguaje. Madrid, Alianza Editorial.

[3] ESPAÑA. MINISTERIO DE EDUCACIÓN, CULTURA Y DEPORTE (2015). El mundo estudia español 2014. Disponible en :

http://www.mecd.gob.es/dctm/redele/MaterialRedEle/el-mundo-estudia-espanol/el-mundo-estudiaespanol2014.pdf?documentld=0901e72b81c71bd2

[4] GARCÍA CASTELLÓN, M. (1998). «Lengua y letras hispánicas en Filipinas. Síntesis histórica y elegía». Centenario de 1898 en Cartagena, pp. 149-170. 
[5] IT \& BP ASSOCIATION OF THE PHILIPPINES IBPAP (2016). IBPAP General Membership Meeting presentation, noviembre de 2015. Disponible en: http://www.ibpap.org/

[6] MIGRATION POLICY INSTITUTE (2016). Disponible en: http://www.migrationpolicy.org/

[7] MOLINA, A. (1998). «¿Qué queda de España en Filipinas?». SECl, $n^{\circ}$ 2, pp: 1-14 Disponible en: http://www.ucm.es/info/seeci/Numeros/Numero2/ InicioN2.html
[8] QUILIS, A. y CASADO, C. (2008). La lengua española en Filipinas. Madrid: Consejo Superior de Investigaciones Científicas.

[9] RODAO, F. (1996). «La lengua española en Filipinas durante la primera mitad del siglo $X X$ ». Estudios de Asia y África, vol. XXXI, pp 157-175.

[10] US CENSUS BUREAU (2016). Language use. Disponible en:

http://www.census.gov/topics/population/languageuse.html 